\title{
Prevalence, resistance pattern, and molecular characterization of Staphylococcus aureus isolates from healthy animals and sick populations in Henan Province, China
}

Baoguang Liu ${ }^{1 \dagger}$, Huarun Sun ${ }^{1 \dagger}$, Yushan Pan ${ }^{1 \dagger}$, Yajun Zhai ${ }^{1}$, Tian Cai ${ }^{1}$, Xiaoling Yuan ${ }^{2}$, Yanling Gao ${ }^{3}$, Dandan He ${ }^{1}$, Jianhua Liu', Li Yuan ${ }^{1 *}$ and Gongzheng Hü ${ }^{1 *}$

\begin{abstract}
Background: Staphylococcus aureus is one of the most prevalent pathogens and a causative agent of a variety of infections in humans and animals. A total of 640 samples were collected from healthy animals and patients from 2013 to 2014 in Henan Province, China, to investigate the prevalence and perform molecular characterization of S. aureus. Antimicrobial resistance and virulence genes were determined and pulsed-field gel electrophoresis (PFGE) and staphylococcal cassette chromosome mec (SCCmec) typing were performed.

Results: Overall, 22.3\% $(n=143)$ of the samples were positive for $S$. aureus. The prevalence of methicillin-resistant $S$. aureus (MRSA) was 5.59\%. Capsular polysaccharide locus type 5 (Cap5; 56.64\%) was the dominant serotype. S. aureus strains showed high resistance to penicillin (96.50\%), ciprofloxacin (52.45\%), amikacin (67.83\%), erythromycin (96.50\%), lincomycin (97.20\%), and tetracycline (68.53\%) and 109 (76.2\%) isolates harbored six or more tested resistance genes. The most predominant resistance genes were aphA (52.45\%), ermC (53.15\%), and tetM (52.45\%). Eighty-seven (60.8\%) isolates harbored six or more tested virulence genes. The most predominant enterotoxin genes were sed (20.28\%), sej (20.98\%), sep (14.69\%), and set (37.76\%). The prevalence of lukED gene was (57.34\%), and a small number of isolates carried pvl (5.59\%) and TSST-1 (2.80\%). A total of 130 (82.52\%) isolates could be typed by PFGE with Smal digestion. PFGE demonstrated that 45 different patterns (P) that were grouped into 17 pulsotypes and 28 separate pulsotypes using a $90 \%$ cut-off value. A total of $118(82.52 \%)$ isolates were successfully typed by spa, and 26 spa types were identified, t15075 (14.00\%) and t189 (12.59\%) were the most common types. SCCmec types were detected from eight MRSA isolates, with the most prevalent type being SCCmec IVa. MRSA-SCCmec Iva-t437 was observed in human isolates.

Conclusion: This study revealed a high prevalence of S. aureus in healthy animals and patients from Henan Province, China. Resistant S. aureus exhibited varying degrees of multidrug resistance. The presence of antibiotic resistance and virulence genes may facilitate the spread of S. aureus strains and pose a potential threat to public health, highlighting the need for vigilant monitoring of these isolates at the human-animal interface.
\end{abstract}

Keywords: Staphylococcus aureus, MRSA, Antimicrobial resistance, PFGE, Spa typing

\footnotetext{
*Correspondence: yuanli-hn@163.com; yaolilab@163.com

${ }^{\dagger}$ Baoguang Liu, Huarun Sun and Yushan Pan contributed equally to this

work

${ }^{1}$ College of Animal Husbandry and Veterinary Science, Henan

Agricultural University, No. 95 Wenhua Road, Zhengzhou, China

Full list of author information is available at the end of the article
}

(c) The Author(s) 2018. This article is distributed under the terms of the Creative Commons Attribution 4.0 International License (http://creativecommons.org/licenses/by/4.0/), which permits unrestricted use, distribution, and reproduction in any medium, provided you give appropriate credit to the original author(s) and the source, provide a link to the Creative Commons license, and indicate if changes were made. The Creative Commons Public Domain Dedication waiver (http://creativecommons.org/ publicdomain/zero/1.0/) applies to the data made available in this article, unless otherwise stated. 


\section{Background}

Staphylococcus aureus, a Gram-positive bacterium, is a causative agent of a variety of infections in humans and animals [1]. Many of the illnesses of humans, such as pneumonia and endocarditis, are related to S. aureus [2]. In animals, $S$. aureus is associated with bovine mastitis, one of the most cost-intensive diseases in the food industry. Bovine mastitis is an infectious disease responsible for significant financial losses to dairy and food farmers worldwide [3]. Since methicillin-resistant S. aureus (MRSA) was first reported in the United Kingdom, it has become a particular public threat to human health, and various hospital-associated MRSA (HA-MRSA) clones have been disseminated worldwide [4]. Since the 1990s, community-associated MRSA (CA-MRSA) has emerged as a serious health problem worldwide [5], first in communities and later in healthcare facilities. However, livestock-associated MRSA (LA-MRSA) clones,such as LA-MRSA ST398 may be transmitted to humans and have posed public health concerns [6]. Therefore, it is imperative to perform surveillance at the interface between human and animal hosts to explore human health risks [7].

The emergence of multidrug resistant (MDR) strains poses several challenges to the clinical facilities [8]. In particular, the increasing prevalence of antimicrobialresistant $S$. aureus serves as a threat to the healthcare system $[9,10]$. On the other hand, most $S$. aureus strains are able to produce a large number of virulence factors, including staphylococcal enterotoxins (SEs), exfoliative toxin (ET) and toxic shock syndrome toxin-1 (TSST-1) genes. Moreover, the production of SEs is particularly significant, as the ingestion of the preformed toxins is a major cause of foodborne poisoning wordwide [11]. $S$. aureus has not only has been isolated from raw milk, a potential reservoir of $S$. aureus, but also from the environments and workers of dairy farms [12, 13]. In addition, studies have reported that some $S$. aureus strains persist in powdered infant formula [1]. However, reports on $S$. aureus isolation from raw milk of healthy animals are relatively scanty. Very little is known about the antimicrobial susceptibility, resistance genes of enterotoxigenic $S$. aureus strains, and the prevalence and molecular characterization of S. aureus isolates.

The aim of the present study was to investigate the prevalence and perform molecular characterization of $S$. aureus isolates from healthy animals and patients in Henan Province, China. Furthermore, we evaluated the antimicrobial susceptibility, resistance genes, virulence genes of these isolates and characterize the molecular types by pulsed-field gel electrophoresis (PFGE), spa, and SCCmec.

\section{Results}

Isolation and identification of $S$. aureus

A total of 143 (22.3\%, 95\% confidence interval [CI] 19.125.6) S. aureus isolates were recovered from 640 samples in Henan province between 2013 and 2014 (Table 1). Two types of samples including animal samples $(\mathrm{n}=548$, 130 isolates, $23.7 \%$, 95\% CI 20.1-27.3) and patient samples $(\mathrm{n}=92,13$ isolates, $14.1 \%, 95 \%$ CI 6.9-21.4) were obtained. A total of 548 animal samples included 350 (22.9\%, 95\% CI 18.4-27.3) raw milk samples, 86 (25.6\%, 95\% CI 16.2-35.0) swine samples, $70(21.4 \%, 95 \%$ CI 11.6-31.3) chicken samples and 42 (31.0\%, 95\% CI 16.445.5) duck samples. Of 92 patient samples, 48 (27.1\%, 95\% CI 14.0-40.1) were obtained from the First Affiliated Hospital of Zhengzhou University and 44 (0.0\%, 95\%

Table 1 Prevalence and detection of nuc and mecA of S. aureus isolates from animals and hospitals

\begin{tabular}{|c|c|c|c|c|c|c|}
\hline \multirow[t]{2}{*}{ Source } & \multirow[t]{2}{*}{ Sampling sites } & \multirow[t]{2}{*}{ No. of samples } & \multirow[t]{2}{*}{ Prevalence (\%) } & \multirow[t]{2}{*}{$95 \% \mathrm{Cl}$} & \multicolumn{2}{|c|}{ Specific gene (\%) } \\
\hline & & & & & nuc & mecA \\
\hline \multicolumn{7}{|l|}{ Animal (healthy) } \\
\hline Cow (raw milk) & 8 & 350 & $22.9(80 / 350)$ & $18.4-27.3$ & $22.9(80 / 350)$ & $1.25(1 / 80)$ \\
\hline Swine (nasal swab) & 2 & 86 & $25.6(22 / 86)$ & $16.2-35.0$ & $25.6(22 / 86)$ & $0(0 / 22)$ \\
\hline Chicken (faecal swab) & 2 & 70 & $21.4(15 / 70)$ & $11.6-31.3$ & $21.4(15 / 70)$ & $6.67(1 / 15)$ \\
\hline Duck (faecal swab) & 2 & 42 & $31.0(13 / 42)$ & $16.4-45.5$ & $31.0(13 / 42)$ & $0(0 / 13)$ \\
\hline Total & 13 & 548 & $23.7(130 / 548)$ & $20.1-27.3$ & $23.7(130 / 548)$ & $1.54(2 / 130)$ \\
\hline \multicolumn{7}{|l|}{ Human (patients) } \\
\hline $\mathrm{A}^{\mathrm{a}}$ (specimens) & 1 & 48 & $27.1(13 / 48)$ & $14.0-40.1$ & $27.1(13 / 48)$ & $46.16(6 / 13)$ \\
\hline $\mathrm{B}^{\mathrm{b}}$ (specimens) & 1 & 44 & $0(0 / 44)$ & $0.0-0.0$ & $0(0 / 44)$ & $0(0 / 0)$ \\
\hline Total & 2 & 92 & $14.1(13 / 92)$ & $6.9-21.4$ & $14.1(13 / 92)$ & $46.16(6 / 13)$ \\
\hline All total & 15 & 640 & $22.3(143 / 640)$ & $19.1-25.6$ & $22.3(143 / 640)$ & $5.59(8 / 143)$ \\
\hline
\end{tabular}

\footnotetext{
a The First Affiliated Hospital of Zhengzhou University
}

b Henan Province People's Hospital 
CI 0.0-0.0), from the Henan Province People's Hospital. Table 1 shows the prevalence of $S$. aureus in animals $(23.7 \%)$, with a higher rate in chicken and duck $(\mathrm{p}>0.05)$; in patients $(14.1 \%)$, with differences rate in chicken and pork $(\mathrm{p}<0.05)$.

\section{Prevalence of MRSA}

As shown in Table 1, the prevalence of MRSA was $5.59 \%$ (8/143). Eight strains carrying mecA were classified as MRSA. The sources of these strains were as follows: 1 strain from raw milk, 1 from chicken, and 6 from patients. The prevalence of raw milk isolates, chicken isolates, and patient isolates were $1.25 \%(1 / 80), 6.67 \%(1 / 15)$, and $46.15 \%(6 / 13)$, respectively. Of note, the prevalence of patient isolates was significantly higher than that of raw milk isolates and chicken isolates.

\section{Determination of $S$. aureus serotypes}

Eighty-one strains $(56.64 \%, 81 / 143)$ were capsular polysaccharide locus type 5 (Cap5), 36 strains (25.17\%, 36/143) were identified as Cap 8 type, and the remaining 26 strains $(18.18 \%, 26 / 143)$ were Cap non-typeable. Therefore, Cap 5 was the dominant serotype observed.

\section{Antimicrobial susceptibility testing}

The results of the antimicrobial susceptibility of all $S$. aureus strains are listed in Table 2. Most S. aureus strains showed high resistance to penicillin $(138,96.50 \%)$, ciprofloxacin $(75,52.45 \%)$, enrofloxacin $(81,56.64 \%)$, gentamicin (116, 81.12\%), amikacin (97, 67.83\%), tylosin (109, 76.22\%), erythromycin $(138,96.50 \%)$, lincomycin $(139,97.20 \%)$, tetracycline $(98,68.53 \%)$, and olaquindox (137, 95.80\%). Moderate resistance was observed for florfenicol, doxycyclin, mequindox, rifampicin and bacitracin, as evident from a resistance of $28.67,46.15,18.18$, 51.05 , and $24.48 \%$, respectively. The rate of resistance to fosfomycin and linezolid was below $20 \%$. None of the eight mecA-positive isolates was susceptible to oxacillin. Some $S$. aureus isolates were deemed methicillin-resistant by susceptibility testing but lacked mecA gene. All $S$. aureus isolates were susceptible to vancomycin. In addition, tigecycline, a new class of glycylcyclines, showed good activity against $S$. aureus with a minimum inhibitory concentration $\left(\mathrm{MIC}_{50}\right)$ of $0.5 \mu \mathrm{g} / \mathrm{mL}$. Tigecycline is known to exhibit broad-spectrum activity against most Gram-positive bacteria.

Multidrug resistance was defined as resistance to three or more different classes of antimicrobials. A total of 143 S. aureus strains exhibited varying degrees of Multidrug resistance (Table 3). In total, 4.20, 3.50, and 6.29\% of strains were resistant to three ( $p>0.05)$, four $(\mathrm{p}<0.01)$, and five $(p>0.05)$ drug classes, respectively. However, $11.89 \%$ of strains were resistant to six $(p>0.05)$ and seven
( $\mathrm{p}>0.05)$ drug classes. In addition, 23.08, 13.29, 18.18, and $7.69 \%$ of strains were resistant to eight $(\mathrm{p}<0.05)$, nine ( $\mathrm{p}>0.05), 10(\mathrm{p}<0.01)$, and $11(\mathrm{p}<0.01)$ drug classes, respectively.

\section{Prevalence of resistance genes and integrons}

The distribution of resistance genes between the different $S$. aureus sources is shown in Additional file 1: Table S1 and Fig. 1. A total of $143 \mathrm{~S}$. aureus isolates were tested for 46 resistance genes. Of these genes, 34 (73.91\%, $34 / 46)$ were detected, and $12(26.09 \%, 12 / 46)$, undetected. Overall, tetracycline resistance was reported in $143 \mathrm{~S}$. aureus isolates, probably owing to the presence of the membrane-associated efflux gene tet $K(32,22.38 \%)$ or the ribosome-binding site gene $\operatorname{tet} M(75,52.45 \%)$. Aminoglycosides resistance genes $\operatorname{acc}\left(6^{\prime}\right)-\operatorname{aph}\left(2^{\prime \prime}\right)$, ant $\left(4^{\prime}\right)$ $I a$, and $a p h A$ were detected in 46 (32.87\%), 25 (17.48\%), and $75(52.45 \%)$ isolates, respectively. Macrolides resistance genes $\mathrm{erm} A$, ermB, and $\mathrm{ermC}$ were detected in 33 (23.08\%), 67 (46.85\%), and 76 (53.15\%) isolates, respectively, while lincosamides resistance genes $\ln u(A)$ and $\ln u(B)$ were detected in $15(10.49 \%)$, and $6(4.20 \%)$ isolates, respectively, $\ln u(C)$ and $\ln u(D)$, were undetected. Streptogramins, lincosamides, and pleuromutilin resistance genes $v g a(A)$ was detected in $12(8.39 \%)$ isolates, while only four isolates carried $v g a(C)$. Olaquindox resistance was related to the associated efflux genes $o q x A$ ( 8 , $5.59 \%)$ and $o q x B(13,9.09 \%)$. The integrase genes of class I, II, and III were detected in 26 (18.18\%), 19 (13.29\%), and $13(9.09 \%)$ isolates, respectively. Resistance genes for fluoroquinolones and mutations (aac(6)-Ib-cr, qepA, $q n r A, q n r B, q n r C, q n r D, q n r S, \operatorname{gyr} A, \operatorname{gyr} B, \operatorname{grl} A$ and $\operatorname{grl} B)$ are summarized in Additional file 1: Table S1.

Of all 143 S. aureus isolates, 7 (4.90\%) isolates carried $\beta$-lactamase gene blaZ, 91 (63.64\%) isolates were positive for the rifampicin resistance gene $r p o B$, and 22 (15.38\%) carried the chloramphenicol and florfenicol resistance gene $f e x A$. In addition, nine (6.29\%) isolates had the oxazolidinone resistance gene optrA, while the bacitracin resistance gene $b c r B$ was detected in $22(15.38 \%)$ isolates. However, the vancomycin resistance gene vanA, fosfomycin resistance gene fos $B$, chloramphenicol and florfenicol resistance gene $c f r$, and bacitracin resistance genes $(b c r A$, $b c r D$, and $b c r R$ ) were absent in all isolate.

\section{Prevalence of virulence genes}

The distribution of virulence genes between the different S. aureus sources is shown in Additional file 1: Table S1 and Fig. 2. A total of $143 \mathrm{~S}$. aureus isolates were tested for 24 virulence genes. Among these genes, 21 (87.50\%, $21 / 24)$ were detected, and $3(12.50 \%, 3 / 24)$, undetected. A more diverse range of enterotoxin genes were detected among these isolates, including sea $(4,2.80 \%)$, seb (17, 
Table 2 Distribution of MICs and susceptibility of S. aureus isolates $(n=143)$

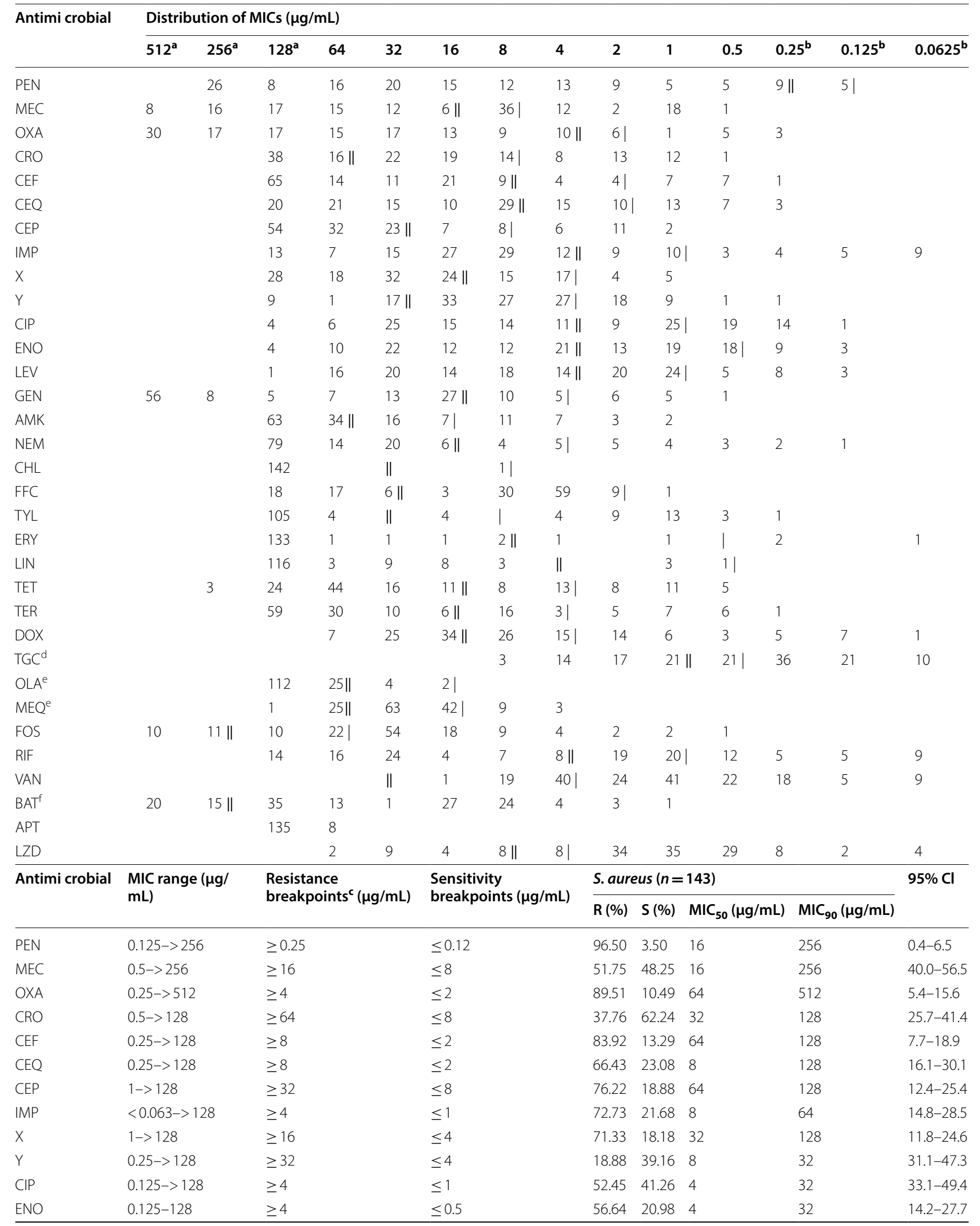


Table 2 (continued)

\begin{tabular}{|c|c|c|c|c|c|c|c|c|}
\hline \multirow[t]{2}{*}{ Antimi crobial } & \multirow{2}{*}{$\begin{array}{l}\text { MIC range }(\mu \mathrm{g} / \\
\mathrm{mL})\end{array}$} & \multirow{2}{*}{$\begin{array}{l}\text { Resistance } \\
\text { breakpoints }^{c}(\mu \mathrm{g} / \mathrm{mL})\end{array}$} & \multirow{2}{*}{$\begin{array}{l}\text { Sensitivity } \\
\text { breakpoints }(\mu \mathrm{g} / \mathrm{mL})\end{array}$} & \multicolumn{4}{|c|}{ S. aureus $(n=143)$} & \multirow[t]{2}{*}{$95 \% \mathrm{Cl}$} \\
\hline & & & & $\mathrm{R}(\%)$ & S (\%) & $\mathrm{MIC}_{50}(\mu \mathrm{g} / \mathrm{mL})$ & $\mathrm{MIC}_{90}(\mu \mathrm{g} / \mathrm{mL})$ & \\
\hline LEV & $0.125->128$ & $\geq 4$ & $\leq 1$ & 58.04 & 27.97 & 4 & 64 & $20.5-35.4$ \\
\hline GEN & $0.5->512$ & $\geq 16$ & $\leq 4$ & 81.12 & 11.89 & 64 & 512 & $6.5-17.3$ \\
\hline AMK & $1->128$ & $\geq 64$ & $\leq 16$ & 67.83 & 20.98 & 64 & 128 & $14.2-27.7$ \\
\hline NEM & $0.125->128$ & $\geq 16$ & $\leq 4$ & 83.22 & 13.99 & 128 & 128 & $8.2-19.7$ \\
\hline $\mathrm{CHL}$ & $8->128$ & $\geq 32$ & $\leq 8$ & 99.30 & 0.70 & 128 & 128 & $0.7-2.1$ \\
\hline FFC & $1->128$ & $\geq 32$ & $\leq 2$ & 28.67 & 6.99 & 8 & 128 & $2.8-11.2$ \\
\hline TYL & $0.25->128$ & $\geq 32$ & $\leq 8$ & 76.22 & 20.98 & 128 & 128 & $14.2-27.7$ \\
\hline ERY & $<0.063->128$ & $\geq 8$ & $\leq 0.5$ & 96.50 & 2.10 & 128 & 128 & $0.3-4.5$ \\
\hline LIN & $0.5->128$ & $\geq 4$ & $\leq 0.5$ & 97.20 & 0.70 & 128 & 128 & $0.7-2.1$ \\
\hline TET & $0.5-256$ & $\geq 16$ & $\leq 4$ & 68.53 & 25.87 & 32 & 128 & $18.6-33.1$ \\
\hline TER & $0.5->128$ & $\geq 16$ & $\leq 4$ & 73.43 & 15.38 & 64 & 128 & $9.4-21.4$ \\
\hline DOX & $<0.063-64$ & $\geq 16$ & $\leq 4$ & 46.15 & 35.66 & 8 & 32 & $27.7-43.6$ \\
\hline$T G C^{d}$ & $<0.063-8$ & $>0.5$ & $\leq 0.5$ & 38.46 & 61.54 & 0.5 & 4 & $53.5-69.6$ \\
\hline OLA ${ }^{e}$ & $16->128$ & $\geq 64$ & $\leq 16$ & 95.80 & 1.40 & 128 & 128 & $0.5-3.3$ \\
\hline $\mathrm{MEQ}^{\mathrm{e}}$ & $2-128$ & $\geq 64$ & $\leq 16$ & 18.18 & 37.76 & 32 & 64 & $29.7-45.8$ \\
\hline FOS & $0.5->512$ & $\geq 256$ & $\leq 64$ & 14.69 & 78.32 & 32 & 256 & $71.5-85.2$ \\
\hline RIF & $<0.063->128$ & $\geq 4$ & $\leq 1$ & 51.05 & 35.66 & 4 & 64 & $27.7-43.6$ \\
\hline VAN & $<0.063-16$ & $\geq 32$ & $\leq 4$ & 0 & 86.01 & 1 & 8 & $80.3-91.8$ \\
\hline $\mathrm{BAT}^{\mathrm{f}}$ & $1->512$ & $\geq 256$ & - & 24.48 & - & 64 & 512 & - \\
\hline APT & $64->128$ & - & - & - & - & 128 & 128 & - \\
\hline LZD & $<0.063-64$ & $\geq 8$ & $\leq 4$ & 16.08 & 83.92 & 1 & 16 & $77.8-90.0$ \\
\hline
\end{tabular}

$P E N$ penicillin, $M E C$ methicillin, OXA oxacillin, $C R O$ ceftriaxone, $C E F$ ceftiofur, $C E Q$ cefquinome, $C E P$ cefepime, IMP imipenem, $X$ cefoperazone and sulbactam sodium (2:1), Y piperacillin and tazobactam sodium (4:1), CIP ciprofloxacin, ENO enrofloxacin, LEV levofloxacin, GEN gentamicin, $A M K$ amikacin, NEM neomycin, CHL chloramphenicol, FFC florfenicol, TYL tylosin, ERY erythromycin, LIN lincomycin, TET tetracycline, TER terramycine, DOX doxycyclin, TGC tigecycline, OLA olaquindox, MEQ mequindox, FOS fosfomycin, RIF rifampicin, VAN vancomycin, BAT Bacitracin, APT antimicrobial peptide, LZD linezolid

a Including higher than this tested MIC value

b Including lower than this tested MIC value

c MIC $(\mu \mathrm{g} / \mathrm{mL})$ results were calculated according to CLSI (2013) breakpoint criteria

$d$ The breakpoints for tigecycline was interpreted according to criteria of the European Committee on Antimicrobial Susceptibility Testing (EUCAST)

e The breakpoints for olaquindox and mequindox were based on Reference values [56]

f Reference the reports [39]

Table 3 Distribution of multidrug-resistance in S. aureus isolates $(n=143)$

\begin{tabular}{|c|c|c|c|c|c|c|c|}
\hline \multirow[t]{2}{*}{ Resistance pattern } & \multicolumn{4}{|c|}{ Animal isolates } & \multirow[t]{2}{*}{ Human isolates $(n=13)$} & \multirow[t]{2}{*}{ Total (\%) } & \multirow[t]{2}{*}{$p$-value ${ }^{a}$} \\
\hline & $\operatorname{Cow}(n=80)$ & Swine $(n=22)$ & Chicken $(n=15)$ & Duck $(n=13)$ & & & \\
\hline$\equiv$ & 4 & 1 & & & 1 & $6(4.20)$ & 0.78 \\
\hline 四 & 2 & & 3 & & & $5(3.50)$ & 0.007 \\
\hline 五 & 6 & & 1 & & 2 & $9(6.29)$ & 0.358 \\
\hline 六 & 12 & 2 & 1 & 1 & 1 & $17(11.89)$ & 0.785 \\
\hline 七 & 9 & 5 & & 1 & 2 & $17(11.89)$ & 0.298 \\
\hline 八 & 25 & 6 & 1 & & 1 & $33(23.08)$ & 0.025 \\
\hline 九 & 11 & 4 & 1 & 1 & 2 & $19(13.29)$ & 0.836 \\
\hline+ & 9 & 3 & 7 & 5 & 2 & $26(18.18)$ & 0.005 \\
\hline+- & 2 & 1 & 1 & 5 & 2 & $11(7.69)$ & 0.000 \\
\hline
\end{tabular}

${ }^{a}$ The positive rates of resistance pattern among human isolates were compared with those among non-human isolates 


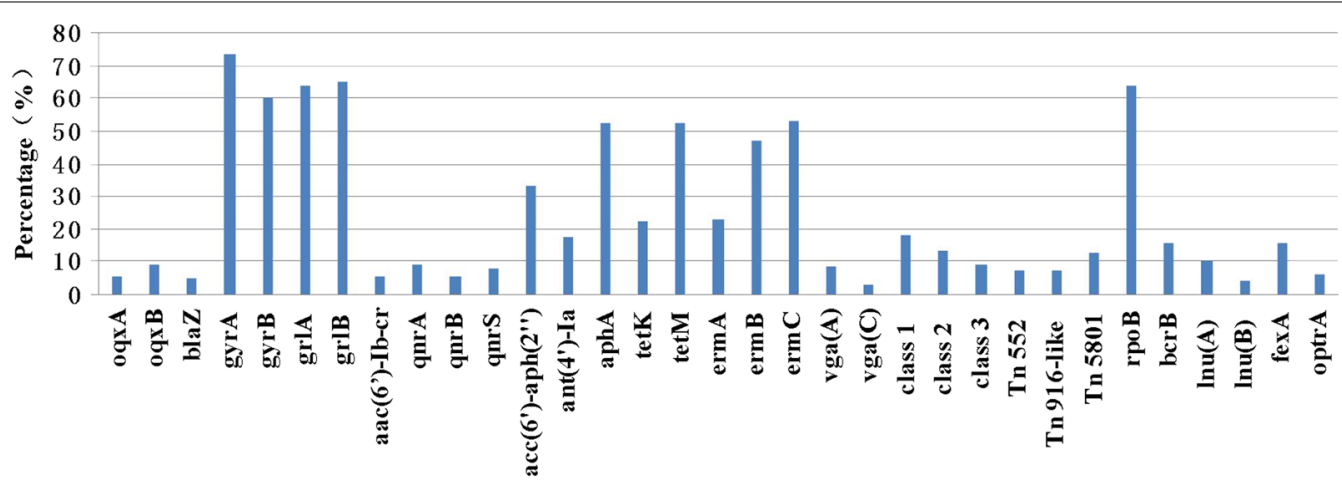

Resis tance genes

Fig. 1 Percentage of positive resistance genes in Staphylococcus aureus isolates. The graph's horizontal axis shows the each of resistance genes, and the vertical axis shows the percentages

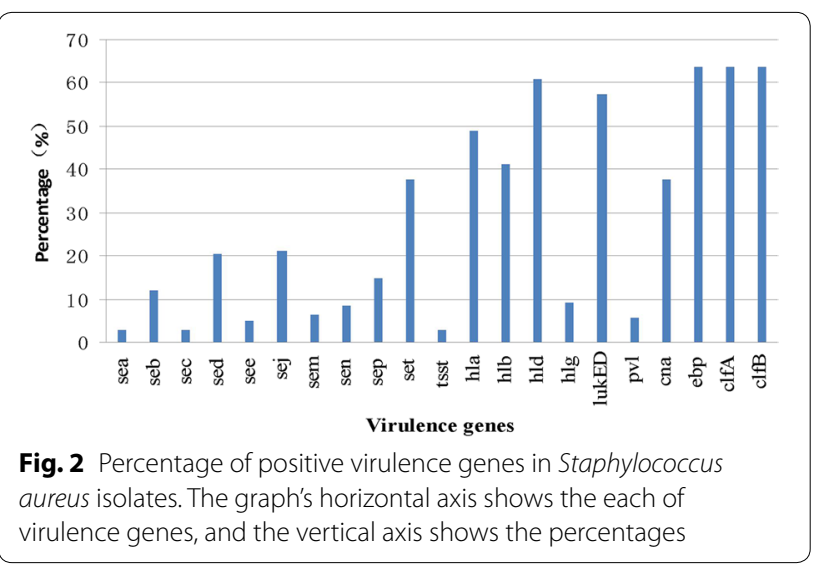

$11.89 \%)$, sec $(4,2.80 \%)$, sed (29, 20.28\%), see (7, 4.90\%), sej (30, 20.98\%), sem (9, 6.29\%), sen (12, 8.39\%), sep (21, $14.69 \%)$ and set (54, 37.76\%).

As shown in Additional file 1: Table S1, the TSST-1 virulence gene was detected in only four (2.80\%) isolates. The $\beta$-hemolysin genes $h l a, h l b, h l d$, and $h l g$ were identified in 70 (48.95\%), 59 (41.26\%), 87 (60.84\%), and 13 $(9.09 \%)$ isolates, respectively. The Panton-Valentine leukocidin $(P V L)$ virulence genes were tested among these isolates, and the majority of the strains carried the $l u k E D$ gene $(82,57.34 \%)$, while a small number of isolates carried $p v l$ gene $(8,5.59 \%)$. However, the adherence factor gene cna was detected in $54(37.76 \%)$ isolates and all of genes $e b p$, clfA, and $c l f B$ were detected in 91 (63.64\%) isolates. All the isolates were negative for the exfoliative toxin genes eta, etb, and etd. A high prevalence of virulence genes $e b p, c l f A, c l f B, h l a, h l d$, and $l u k E D$ was observed in $143 \mathrm{~S}$. aureus isolates.

\section{Genomic macrorestriction and PFGE typing}

We performed PFGE-typing for all 143 S. aureus isolates, and only $130(82.52 \%)$ isolates could be typed using DNA macrorestriction followed by PFGE with Sma I digestion. These $130 \mathrm{~S}$. aureus isolates revealed 45 different electrophoretic patterns (P) with homologies between $41.4 \%$ and $100 \%$. These were grouped into 17 pulsotypes (P1P17) and 28 separate pulsotypes using a $90 \%$ cut-off value (Fig. 3). The analysis of 130 isolates that were grouped into 10 major pulsotypes designated as P1 (17/130), P2 (15/130), P3 (11/130), P4 (7/130), P5 (6/130), P6 (5/130), P7 (5/130), P8 (5/130), P9 (5/130), and P10 (5/130) accounted for $62.3 \%$ of these isolates. The two main clusters $\mathrm{P} 1$ and $\mathrm{P} 2$ contained 17 and 15 isolates, respectively.

Two PFGE pulsotypes, P7 and P12, were detected in all three geographic regions, while PFGE pulsotypes P18, $\mathrm{P} 16$, and P17, each with only one or two isolates, were more unevenly distributed (Fig. 3). Strains isolated from swine, as well as from the chickens or raw milks were present in these difference clusters, suggestive of the possible transmission through the swine farm or slaughtering procedure (Fig. 3). Identical the same PFGE patterns were observed for strains from swine, chicken, and raw milk, indicating that the infection was probably acquired through the spread of $S$. aureus.

\section{Spa typing}

Spa typing was performed for all $143 \mathrm{~S}$. aureus isolates. Only $118(82.52 \%)$ isolates were successfully confirmed and these were assigned to 26 spa types, which varied in length between 1 and 10 repeat units (Table 4).

Among the $118 \mathrm{~S}$. aureus isolates, a diverse range of spa types were detected; $\mathrm{t} 15075(20 / 118,14.00 \%)$ was the most common type, followed by t189 (18/118, 12.59\%), t034 (12/118, 8.39\%), t091 (10/118, 7.00\%), t127 (9/118, $6.29 \%)$, and t164 (8/118, 5.60\%). However, only t034 $(12 / 118,8.39 \%)$ was present in isolates from the three animals sources. The distribution of the 118 S. aureus spa types are correlated with the repeat units (Table 4). 


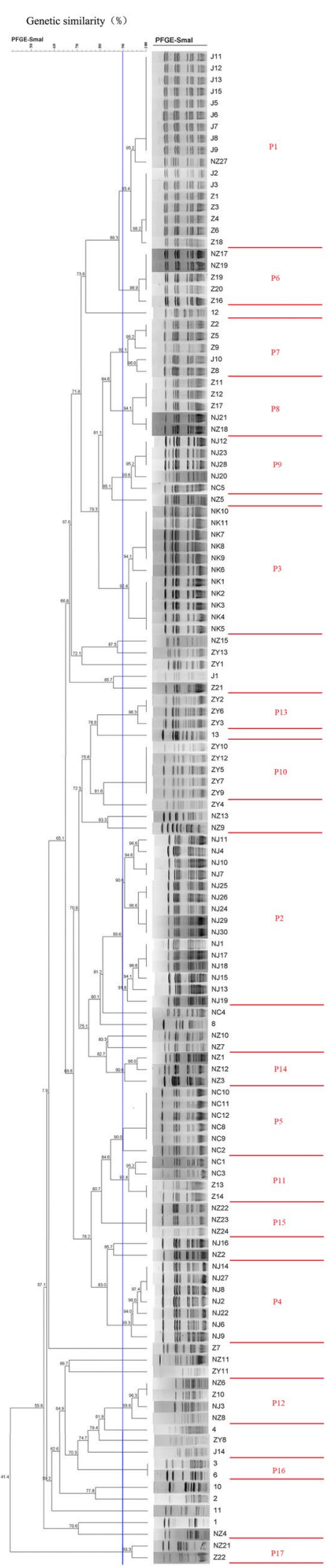

Fig. 3 Dendrogram of PFGE profiles of Sma I-digested Genomic DNA of genetically unrelated $S$. aureus isolates. Similarities percentage is identified on a dendrogram derived from the unweighted pair group method using arithmetic averages and based on Dice coefficients.

The vertical blue line shows the $90 \%$ similarity cut-off, whilst the pulsotypes are delineated by red lines

\section{SCCmec typing}

Of the eight MRSA isolates, SCCmec was detected in seven isolates. The most prevalent type was SCCmec IVa $(\mathrm{n}=3)$, followed by SCCmec III $(\mathrm{n}=2)$, SCCmec II $(\mathrm{n}=1)$, and SCCmec I $(\mathrm{n}=1)$. One MRSA isolates could not be SCCmec typed.

\section{Discussion}

In this study, we investigated the prevalence and performed molecular characterization of $S$. aureus isolated from Henan province, China, to facilitate better understanding of the epidemiology of S. aureus. We found that the prevalence of $S$. aureus strains was $22.3 \%$, consistent with the previous reports [14], but was significantly higher than that reported in other countries $[15,16]$. Unlike a previous study [1] where in all S. aureus samples were collected from animals and humans, more than $90 \%$ of the $143 \mathrm{~S}$. aureus isolates in the present study were recovered from healthy animals. The percentage of animal samples positive for $S$. aureus (23.7\%) in our study was similar to that previously reported [17]. However, some previous studies have detected higher percentages [18], while others have reported lower percentages [11, 12]. The percentage of human samples detected positive for $S$. aureus ( $\mathrm{n}=92,13$ isolates, 14.1\%) in our study was similar to that reports in a previous study [19], but other studies have detected higher percentages [20] and some studies have reported lower percentages [21]. In addition, none of the 44 samples from the Henan Province People's Hospital was found positive, probably owing to the difference in the nature or source of samples. Hence, further studies are warranted.

In the present study, the prevalence of MRSA was only $5.59 \%$. MRSA is known to cause a wide variety of infections in humans and animals. Very little is known about the frequency of MRSA transmission between animals and humans,but MRSA transmission from healthy animals poses a great threat to medical science and veterinarian clinic. As observed with S. aureus, MRSA may cause some infections in humans and animals. The percentages of MRSA detected in other studies have been variable [20-22]. Studies on the prevalence of MRSA in China have detected MRSA isolates in animal and human samples [1,23]. MRSA prevalence in China was $27.5 \%$ in 1999 and rapidly reached $60.7 \%$ in 2009 [24]. Other 
Table 4 Prevalence of the spa type among the S. aureus isolates

\begin{tabular}{|c|c|c|c|c|}
\hline Spa types & Spa repeats & Repeat units & Strain number & Total (\%) \\
\hline t030 & r15-r12-r16-r02-r24-r24 & 6 & $\mathrm{ZY} 2, \mathrm{ZY} 3, \mathrm{ZY} 4$ & $3(2.10)$ \\
\hline t034 & r08-r16-r02-r25-r02-r25-r34-r24-r25 & 9 & Z9, Z11, Z14, Z15, J1, J4, J10, NC6, NC8, NC10, NC11, NC12 & $12(8.39)$ \\
\hline t091 & $\begin{array}{l}r 07-r 23-r 21-r 17-r 34-r 12-r 23-r 02-r 12- \\
r 23\end{array}$ & 10 & $\mathrm{Z2}, \mathrm{Z8}, \mathrm{Z10}, \mathrm{Z13}, \mathrm{Z17}, \mathrm{Z21}, \mathrm{NC1}, \mathrm{NC2}, \mathrm{NC3}, \mathrm{NC4}$ & $10(7.00)$ \\
\hline t127 & r07-r23-r21-r16-r34-r33-r13 & 7 & NJ1, NJ7, NJ10, NJ11, NJ13, NJ18, NJ19, NJ24, NJ29 & $9(6.29)$ \\
\hline $\mathrm{t} 164$ & r07-r06-r17-r21-r34-r34-r22-r34 & 8 & NZ3, NZ9, NZ11, NZ15, NZ20, NZ24, NZ25, NZ26 & $8(5.60)$ \\
\hline t189 & r07-r23-r12-r21-r17-r34 & 6 & $\begin{array}{l}\text { NK1, NK2, NK4, NK5, NK7, NK9, NK10, NK11, NJ17, NZ1, NZ5, NZ12, } \\
\text { NZ27, 1, 3, 4, 5, } 10\end{array}$ & $18(12.59)$ \\
\hline t267 & $\begin{array}{l}\text { r07-r23-r12-r21-r17-r34-r34-r34-r33- } \\
\text { r34 }\end{array}$ & 10 & NJ9, NJ16, 13 & $3(2.10)$ \\
\hline t437 & r04-r20-r17-r20-r17-r25-r34 & 7 & ZY1 & $1(0.70)$ \\
\hline $\mathrm{t} 458$ & $\mathrm{r} 26$ & 1 & NJ2, NJ8, NJ14, NJ22, NJ23, NJ28 & $6(4.20)$ \\
\hline t605 & r07-23 & 2 & NJ6 & $1(0.70)$ \\
\hline t693 & r07 & 1 & NJ15 & $1(0.70)$ \\
\hline t730 & r07-r34-r34-r34-r33-r34 & 6 & NZ2 & $1(0.70)$ \\
\hline t865 & r07-r23-r12-r21-r17-r34-r34-r34 & 8 & NJ25 & $1(0.70)$ \\
\hline t899 & r07-r16-r23-r02-r34 & 5 & $\mathrm{Z7,NC5}$ & $2(1.40)$ \\
\hline t2193 & r07-r12-r21-r17-r13-r34-r34 & 7 & ZY11 & $1(0.70)$ \\
\hline t2224 & $\begin{array}{l}\text { r07-r23-r12-r21-r17-r34-r34-r34-r33- } \\
\text { r13 }\end{array}$ & 10 & 12 & $1(0.70)$ \\
\hline t2646 & r26-r17-r34-r17-r17-r16 & 6 & $J 2$ & $1(0.70)$ \\
\hline t3155 & r07-r12-r21-r17-r13-r34-r34-r33-r13 & 9 & ZY6, ZY7, ZY9, ZY10, ZY12 & $5(3.50)$ \\
\hline t3380 & r07-r23-r12-r21-r17-r34-r34 & 7 & NJ26, NZ10 & $2(1.40)$ \\
\hline t3512 & r07-r16-r23-r02 & 4 & $\mathrm{Z12}, \mathrm{NC7}, 8,9,11$ & $5(3.50)$ \\
\hline t3527 & r04-r20-r17-r02-r17-r25-r34 & 7 & ZY13 & $1(0.70)$ \\
\hline t3626 & r07-r23-r12-r21-r17-r34-r34-r34-r33 & 9 & NJ4 & $1(0.70)$ \\
\hline t6367 & r07-r23-r12-r21-r17 & 5 & NK8, NZ7 & $2(1.40)$ \\
\hline t6811 & r07-r23-r21-r16-r34-r33 & 6 & NJ30 & $1(0.70)$ \\
\hline t8139 & r07-r23-r12-r21-r17-rr17 & 6 & NK3, NZ22 & $2(1.40)$ \\
\hline t15075 & r26-r17-r34-r17-r17-r17-r16 & 7 & $\begin{array}{l}\mathrm{Z1}, \mathrm{Z3}, \mathrm{Z4}, \mathrm{Z5}, \mathrm{Z6}, \mathrm{Z16}, \mathrm{Z18}, \mathrm{Z19}, \mathrm{Z20}, \mathrm{Z22}, \mathrm{J3}, \mathrm{J5}, \mathrm{J6}, \mathrm{J7}, \mathrm{J8}, \mathrm{J9}, \mathrm{J11}, \mathrm{J12} \\
\mathrm{J13}, \mathrm{J15}\end{array}$ & $20(14.00)$ \\
\hline no spa $a^{\mathrm{a}}$ & - & - & $\begin{array}{l}\text { J14, NK6, NC9, ZY5, ZY8, NJ3, NJ5, NJ12, NJ20, NJ21, NJ27, NZ4, NZ6, } \\
\text { NZ8, NZ13, NZ14, NZ16, NZ17, NZ18, NZ19, NZ21, NZ23, 2, 6, 7 }\end{array}$ & $25(17.48)$ \\
\hline
\end{tabular}

${ }^{a}$ Not available

studies have reported $69.5 \%$ and $78.5 \%$ MRSA prevalence in Shanghai and Guangzhou, respectively. Inland cities such as Chongqing have been reported to exhibit a prevalence of $45.0 \%$ [25]. In the present study, Cap5 (56.64\%) was detected as the dominant serotype. However, Cap 8 has been reported as the dominant serotype in other studies [26].

In this study, we observed high resistance rates. The resistance rates to penicillin $(96.50 \%)$ and tetracycline (68.53\%) detected in this study were similar to those observed in previous studies $[15,27]$. The high resistance rates may be related to the use of antimicrobials treating mastitis in cattle farm and growth promotion or prophylaxis in swine and chicken. The prevalence of resistance to multiple antibiotics detected in our study was similar to that reported in previous studies [28]. In addition, the antibiotic resistance patterns of $S$. aureus strains recovered from raw milk and dairy products were reported [3]. In our study, oxacillin resistance was detected in strains isolated from raw milk, chicken, and human isolates, in contradiction with the previous reports $[1,29]$. These studies reported that MRSA are only found in pig farms but not in raw milk, chicken, and human isolates. Furthermore, $8 \mathrm{mec} A$-positive isolates were resistant to oxacillin. Previously reported a significant correlation between oxacillin resistance and resistance to ciprofloxacin, clindamycin, gentamycin, and erythromycin [30], consistent with the results of our study. In addition, some $S$. aureus isolates were resistant to methicillin, but lack of $m e c A$ gene, as reported in another study [31]. Therefore, 
phenotypically resistant MRSA could be misdiagnosed using molecular methods alone, suggestive of the multiple mechanisms in MRSA. In addition, tigecycline, showed good activity against $S$. aureus, thereby ensuring effective control efforts in humans. Tigecycline resistance was recently identified for different pathogens, especially in MDR strains [32]. Hence, further studies are needed to evaluate the transmission between animals and humans.

Identification of the mecA gene in S. aureus is a gold standard for the detection of MRSA, which exhibits low affinity for $\beta$-lactam antimicrobials [18]. The blaZ gene confers penicillin resistance. We found that $96.50 \%$ of strains were resistant to penicillin, but only eight $(4.90 \%)$ strains harbored blaZ. This observation is in line with the previously reported results [33]. In our study, both tet $M$ and tet $K$ were detected in tetracycline-resistant strains, whereas approximately $80 \%$ of tetracycline-resistant strains carried tet $M$, as previously observed [33]. In addition, the majority of the strains carried tet $M$ as well as blaZ, consistent with the results of a previous study [34]. Macrolide resistance genes erm $A$, ermB, and erm $C$ were present either alone or in combination with $\operatorname{erm}(A)+\operatorname{erm}(B), \operatorname{erm}(B)+\operatorname{erm}(C)$, or $\operatorname{erm}(A)+\operatorname{erm}(B)+\operatorname{erm}(C)$, which was in accordance with a previous study [35]. In this study, 22 (15.38\%) isolates carried florfenicol resistance gene $f e x A$, and the number was significantly higher than that reported in a previous study [36]. Gentamicin resistance was associated with the aminoglycoside resistance genes $\operatorname{acc}\left(6^{\prime}\right)$-aph $\left(2^{\prime \prime}\right)$, $\operatorname{ant}\left(4^{\prime}\right)-I a$, or $a p h A$, and these three genes co-existed in the majority of isolates, as observed in a previous study [35]. The location of $v g a(A)$ or $v g a(C)$ on a plasmid may play an important role in its persistence and dissemination [22, 37]. Bacitracin, a polypeptide antibiotic, is used as an animal growth promoter for prophylaxis and therapy of consumable animals in China. In the present study, the prevalence of the $b c r B$ gene in swine strains (59.1\%) was higher than that in chicken strains (46.7\%); this observation may be largely related to the wider use of bacitracin as a feed additive in swine than in chicken. To the best of our knowledge, this is the first report to demonstrate $b c r B$ gene in $S$. aureus isolates from animals in Henan province, China. Some recent reports have shown the widespread of the high-level bacitracin resistance (MIC $\geq 256 \mu \mathrm{g} / \mathrm{mL}$ ) in enterococci $[38,39]$. In the present study, the prevalence of linezolid resistance gene optrA in chicken strains (26.7\%) was higher than that in swine strains (13.6\%). This is the first report to detect optrA gene in $S$. aureus isolates from animals in Henan province, China. The gene optrA was recently detected in S. sciuri from swine [40]. Although linezolid is not approved for use in animals, selective pressure from other antibiotics such as florfenicol, tiamulin, and lincomycin that are widely used in animals may promote the spread of optrA. Thus, more attention needs to be paid to the possibility that optrA may find its way through the food chain or pathogenic bacteria of humans. In addition, the emergence and dissemination of these MDR isolates in animals pose a threat to public health, given that optrA-mediated linezolid resistance may rapidly spread among different bacterial species. Therefore, the surveillance of optrA gene in China is very important to limit its dissemination to prevent the potential threat to animal and human health.

The existence of SEs in S. aureus isolated from animals and humans vary from our reported. The results of the present study on the existence of $s e a, s e b$, and sec in all $S$. aureus isolates are contradictory to those previously reported, wherein sea was observed in $45.2 \%$ of isolates and $s e b$ was detected in $18.5 \%$ of isolates [41]. In another study, sea was reported in $26.2 \%$ of isolates and seb in $39.3 \%$ of isolates [23]. However, the detection rate for sec gene was low in $6 \%$ of the isolated $S$. aureus strains [42]. The high occurrence of $\beta$-hemolysin genes hla (48.95\%) and $h l b(41.26 \%)$ among S. aureus isolates is in line with the results of other reports [43]. In our study, the TSST virulence gene associated with TSST-1 was detected in only $4(2.80 \%)$ isolates, consistent with the results of another study [41]. Moreover, more than half of the strains carried $l u k E D$ gene $(57.34 \%)$, as previously reported [19]. In addition, a small number of isolates carried $p v l$ gene $(8,5.59 \%)$, consistent with a previous report [23], and this number was lower than the occurrences of $p v l$-positive $S$. aureus in a previous study [44]. In the present study, four of $p v l$-positive isolates were MRSA, while the remaining four isolates showed different molecular types.

The results of PFGE analysis showed that a part of the isolates were identical and showed the same PFGE patterns (P1). These were derived from swine, chicken, and raw milks of different animals. This observation is in line with that reported in a previous study, wherein same PFGE patterns were observed for strains from goat milk powders at different processing stages [3]. Thus, cross contamination of $S$. aureus may occur in different animals. A previous study showed that each region had its own predominant PFGE pattern [22]. Identical the same PFGE patterns were observed for strains from swine, chicken, and raw milks of different animals, supporting our hypothesis that the infection may be probably acquired through the spread of $S$. aureus. Strains isolated from swine and chicken or raw milks were present in these clusters, suggestive of the possible transmission during the slaughtering procedure as previously reported [15]. As observed in the spa typing results, t15075 and t189 were the most common spa types. However, $t 899$ 
was the most prevalent spa types in $S$. aureus [22, 45]. Although PFGE patterns of the isolates showed more variations than those observed by spa typing, new technologies such as next generation sequencing may provide better understanding of the origin, transmission, and evolution of MRSA. These advanced technologies would be included in our further studies on the origin and spread of MRSA in China [22]. In this study, PFGE and spa typing were used in combination with SCCmec typing. The majority of the strains were assigned to ten major PFGE types, and P1 and P2 were the two most common clusters containing 17 and 15 isolates, respectively. Moreover, PFGE type P1 among three spa types (t15075, t189, and t2646), spa types t189 among main three clusters (P1, P2, and P3). In this study, MRSA-SCCmec Iva-t 437 was observed in human isolates, as previously reported $[23,46]$.

\section{Conclusion}

In conclusion, this study presents the first insight into the prevalence, antimicrobial resistance, virulence factors, and molecular characterization of $S$. aureus isolates from healthy animals and patients in Henan Province, China. The high prevalence of $S$. aureus highlights the importance of effective animal hygiene measures to prevent the further spread of $S$. aureus. It is important to consider the prevalence of $S$. aureus in raw milk and the risk of its transmission through the food chain. Moreover, high resistance rates were observed, necessitating strict supervision. Future epidemiological investigations should be conducted with larger number of strains and samples.

\section{Methods}

\section{Collection of samples}

From September 2013 to June 2014, a total of 640 samples, including 548 animal samples, and 92 patient samples, were collected in Henan province, China. We collected 548 samples (cows, $\mathrm{n}=350$; swine, $\mathrm{n}=86$; chickens, $\mathrm{n}=70$; ducks, $\mathrm{n}=42$ ) from healthy animals in large-scale farms. In addition, 92 patient samples from various clinical specimens were obtained from the First Affiliated Hospital of Zhengzhou University $(n=48)$ and Henan Province People's Hospital $(\mathrm{n}=44)$ in Zhengzhou city. These specimens were recovered from adult humans with symptoms of pneumonia, diarrhea and pyogenic infection. The samples were transported to the laboratory under required preservation conditions (in a cooler with ice) within $6 \mathrm{~h}$ of collection and processed within $2 \mathrm{~h}$.

\section{Isolation and identification of $S$. aureus}

Isolation and identification of $S$. aureus were performed by enrichment and sequential plating onto selective plates, as previously described [47]. The samples were incubated in brain-heart infusion (BHI) (Beijing Land Bridge Technology Co., Ltd, China) broth containing $7.5 \%$ sodium chloride $(\mathrm{NaCl})$ at $37{ }^{\circ} \mathrm{C}$ overnight. Colonies were purified on tryptone soy agar (TSA) plates (Beijing Land Bridge Technology Co., Ltd, China). The broth was streaked onto CHROMagar S. aureus (CHROMagar, France) plates and incubated at $37^{\circ} \mathrm{C}$ for $24 \mathrm{~h}$ to obtain presumptive isolates of $S$. aureus. These presumptive isolates were identified as $S$. aureus following by Gram staining, and catalytic reactions using VITEK-2 compact automated identification system (BioMérieux, MarcyI'Etoile, France). S. aureus ATCC 29213 was used as a positive reference strain.

\section{Molecular identification of thermonuclease (nuc) and mecA genes}

Bacterial genomic DNA was obtained from $2 \mathrm{~mL}$ of the bacterial cell suspension incubated overnight in BHI. Single colonies were grown on BHI agar and transferred to $2 \mathrm{~mL}$ of BHI broth. Then cultures were centrifuged for $8 \mathrm{~min}$ at $12,000 \times \mathrm{g}$, and the DNA pellets were resuspended in $50 \mu \mathrm{l}$ of lysostaphin solution $(30 \mathrm{mg} /$ $\mathrm{mL}$; Shanghai Yuanye Bio-Technology Co., Ltd, China). After $10 \mathrm{~min}$ of incubation at $37^{\circ} \mathrm{C}, 50 \mu \mathrm{l}$ of Proteinase $\mathrm{K}(100 \mathrm{mg} / \mathrm{L})$ and $100 \mu \mathrm{l}$ of TE buffer $(10 \mathrm{mM}$ Tris- $\mathrm{HCl}$ buffer [pH 7.5] and $1 \mathrm{mM}$ ethylenediaminetetraacetic acid [EDTA]) were added; the sample was mixed by vortexing and incubated for $10 \mathrm{~min}$ at $37^{\circ} \mathrm{C}$. The sample were heated in a thermocycler at $99.9^{\circ} \mathrm{C}$ for $10 \mathrm{~min}$ and immediately incubated at $-20^{\circ} \mathrm{C}$ for $15 \mathrm{~min}$, followed by centrifugation at $12,000 \times g$ for $15 \mathrm{~min}$. A total of $100 \mu \mathrm{l}$ of supernatant was removed without disturbing the pellet and dissolved in water, and the extracted genomic DNA was stored at $-20^{\circ} \mathrm{C}$ as a PCR template.

The identity of $S$. aureus isolates were further confirmed by PCR using a species-specific primer (F: 5'-GCGATTGATGGTGATACGGTT-3', R: 5'-AGCCAA GCCTTGACGAACTAAAGC-3') that codes for $n u c$, as previously described [48]. S. aureus (ATCC 29213) was used as a positive control. The identified $S$. aureus isolates were confirmed as MRSA by amplifying the methicillin resistance-encoding $m e c A$ gene with $m e c A$ primers (F: 5'-TCCAGATTACAACTTCACCAGG-3', R: 5'-CCA CTTCATATCTTGTAACG-3') [49].

\section{Identification of S. aureus Cap5 and Cap8}

The serovars of $S$. aureus isolates were determined by Cap tests, Cap5 and Cap 8 were detected according to the previously described method [26].

\section{Antimicrobial susceptibility testing}

The susceptibility of $143 \mathrm{~S}$. aureus to 33 antibiotics in this study was tested (Additional file 2: Table S2) by the 
broth microdilution method according to the Clinical and Laboratory Standards Institute (CLSI) guidelines [50]. MICs for penicillin, methicillin, oxacillin, ceftriaxone, ceftiofur, cefquinome, cefepime, imipenem, cefoperazone and sulbactam sodium (2:1), piperacillin and tazobactam sodium (4:1), ciprofloxacin, enrofloxacin, levofloxacin, gentamicin, amikacin, neomycin, chloramphenicol, florfenicol, tylosin, erythromycin, Lincomycin, tetracycline, terramycine, doxycyclin, tigecycline, olaquindox, mequindox, fosfomycin, rifampicin, vancomycin, bacitracin, antimicrobial peptide, and linezolid were determined.

We used S. aureus ATCC 29213 as a reference strain for quality control in MIC determinations. Results were interpreted in accordance with the CLSI guidelines [50]. If CLSI criteria were unavailable for some antibiotics, results were interpreted according to criteria of the European Committee on Antimicrobial Susceptibility Testing (EUCAST) [51].

\section{Determination of antimicrobial resistance genes and integrons}

Resistance genes for olaquindox (oqxA and $o q x B)$, $\beta$-lactams (blaZ), vancomycin (vanA), fosfomycin (fos $B)$, rifampicin (rpoB), oxazolidinone (optrA), chloramphenicol and florfenicol ( $c f r$ and $f e x A$, respectively), fluoroquinolones and mutations (aac(6')-Ib-cr, qepA, qnrA, qurB, $q n r C$, qnrD, qurS, gyrA, gyrB, grlA, and $\operatorname{grl} B)$, aminoglycosides $\left(\operatorname{acc}\left(6^{\prime}\right)\right.$-aph $\left(2^{\prime \prime}\right)$, ant $\left(4^{\prime}\right)-I a$, and $\left.a p h A\right)$, tetracycline (tetk and tet $M)$, macrolides (ermA, ermB, and erm $C$ ), streptogramins, lincosamides and pleuromutilin $(v g a(A), v g a(B)$, and $v g a(C))$, lincosamides $(\ln u A, \ln u B$, $\ln u C$, and $\operatorname{lnu} D)$, bacitracin (bcrA, $b c r B, b c r D$, and $b c r R)$, integrase genes of class $I, I I$, and $I I I$ were determined by PCR. The primers used and amplicon band sizes are shown in Additional file 3: Table S3. All PCR products were sequenced and compared with sequences in National Center for Biotechnology Information (NCBI; http://www.ncbi.nlm.nih.gov).

\section{Prevalence of virulence genes}

A total of $143 \mathrm{~S}$. aureus isolates were screened for 24 different virulence genes from seven different toxin gene groups, including enterotoxins (sea, seb, sec, sed, see, sej, sem, sen, sep, and set), hemolysins (hla, hlb, hld, and hlg), leucocidin (lukED), Panton-Valentine leucocidin ( $p v l)$, adherence factors ( $c n a, e b p, c l f A$, and $c l f B)$, toxic shock syndrome toxin (TSST), and exfoliative toxins (eta, etb, and $e t d$ ). The primers and amplicon band sizes are listed in Additional file 4: Table S4. At least one representative PCR amplicon of each positive virulence gene was sequenced using the same primers to confirm the accuracy of the PCR amplification.

\section{Pulsed-field gel electrophoresis typing}

We performed PFGE typing according to the CDC standard protocol developed by PulseNet for S. aureus [52]. Genomic DNA of all $143 \mathrm{~S}$. aureus isolates were prepared from $5 \mathrm{~mL} S$. aureus culture grown overnight in Luria-Bertani (LB) broth (Beijing Land Bridge Technology Co., Ltd, China). Briefly, agarose-embedded DNA was digested using the restriction enzyme Sma $I$ (TaKaRa, Dalian) for $6 \mathrm{~h}$ in a water bath at $30{ }^{\circ} \mathrm{C}$. Restriction fragments of DNA were separated by PFGE using 1.0\% Seakem Gold Agarose gels (Lonza, USA) with the PFGE apparatus CHEF Mapper electrophoresis system (Bio-Rad) at $6 \mathrm{~V} / \mathrm{cm}$ and $14{ }^{\circ} \mathrm{C}$ in $0.5 \times \mathrm{TBE}$ buffer for $19 \mathrm{~h}$ with the pulse time ranging from 5.2 to $41 \mathrm{~s}$ at an angle of $120^{\circ}$. After electrophoresis, gels were stained with ethidium bromide and photographed with Gel Doc XR digital imaging system (Bio-Rad) under UV illumination and stored as TIFF files. Gel images were analyzed using BioNumerics Software (version 4.0, Applied Maths, Kortrijk, Belgium). The banding patterns in different gels were clustered using Dice coefficients with $1.4 \%$ band tolerance and $1 \%$ optimization settings, and unweighted pair group method with arithmetic mean (UPGMA) was used to calculate Dice coefficients of correlation. This result corresponded to a similarity coefficient of $90 \%$ was used to define a PFGE cluster (pulsotype, P). Salmonella Branderup strain H9812 was digested with $\mathrm{Xba} I$ (TaKaRa, Dalian) and used as a molecular size marker.

\section{Spa typing}

Spa typing was based on variations of the repeat units; the spa gene from the $\mathrm{X}$ region was amplified by $\mathrm{PCR}$ [53]. Primers $s p a-1113 f\left(5^{\prime}\right.$-TAAAGACGATCCTTCGGT GAGC-3') and spa-1514r (5'-CAGCAGTAGTGCCGT TTGCTT-3') were used for amplification (http://www. ridom.de/doc/Ridom_spa_sequencing.pdf). We assigned spa typing by submitting the data to the SpaServer Database (http://spaserver.ridom.de). The software Ridom StaphType (Ridom GmbH, Würzburg, Germany) was used for spa sequence analysis.

\section{Staphylococcus cassette chromosome mec typing}

Staphylococcus cassette chromosome mec typing was performed using multiplex PCR schemes, as per a previously reported method [54]. MRSA isolates that showed unrelated patterns or could not be assigned to any expected type were defined as non-typable [55].

\section{Data analysis and statistical methods}

All 143 isolated strains were categorized as sensitive (S) or resistant (R) based on the MIC values. The MIC range, $\mathrm{MIC}_{50}$, and $\mathrm{MIC}_{90}$ were analyzed. For statistical analysis, 
Chi square test was performed, and $p$ values of $\leq 0.05$ were considered statistically significant, and $95 \%$ confidence intervals were calculated using SPSS 20.0 software (IBM, USA).

\section{Additional files}

Additional file 1: Table S1. Characteristics of the 143 S. aureus isolates.

Additional file 2: Table S2. A list of the 33 tested antimicrobials, their classes, and the concentrations used for susceptibility testing of $\mathrm{S}$. aureus.

Additional file 3: Table S3. Oligonucleotide sequences, primers, and targets for polymerase chain reaction amplification of antibiotic resistance genes and integrons in S. aureus isolates.

Additional file 4: Table S4. Oligonucleotide sequences, primers, and targets for polymerase chain reaction amplification of virulence genes in S. aureus isolates.

\section{Abbreviations}

S. aureus: Staphylococcus aureus; MRSA: methicillin-resistant S. aureus; FDA: food and drug administration; MDR: multidrug resistant; CLSI: Clinical and Laboratory Standards Institute; MICs: minimum inhibitory concentrations; EUCAST: European Committee on Antimicrobial Susceptibility Testing; SCCmec: Staphylococcus cassette chromosome mec.

\section{Authors' contributions}

BGL and GZH participated in study conception, design and prepared the manuscript. BGL, TC, HRS, YJZ and XLY participated in sample collection and performed the experiments. BGL performed most of the experiments, and reviewed the manuscript. YLG, DDH, JHL and YSP analyzed results and reviewed the manuscript. LY and GZH revised the manuscript and coordinated the whole project. All authors read and approved the final manuscript.

\section{Author details \\ ${ }^{1}$ College of Animal Husbandry and Veterinary Science, Henan Agricultural University, No. 95 Wenhua Road, Zhengzhou, China. ${ }^{2}$ Neonatal Intensive Care Unit, First Affiliated Hospital of Zhengzhou University, No. 1 Jianshe Road, Zhengzhou, China. ${ }^{3}$ Animal Husbandry Bureau of Henan Province, No. 91 Jingsan Road, Zhengzhou, China.}

\section{Acknowledgements}

We thank Chengguang Zhang (Huazhong Agricultural University, CHINA) for reading this manuscript and providing helpful feedback, and thank the key laboratory for animal-derived food safety of Henan Province.

\section{Competing interests}

The authors declare that they have no competing interests.

\section{Availability of data and materials}

All data generated or analyzed during this study are included in this published article and its additional information files.

\section{Consent for publication}

Not applicable.

\section{Ethics approval and consent to participate}

With regards to our study's use of animals, this study protocol was reviewed and approved by the Henan Agriculture University animal ethics committee, and the experiment was performed in accordance with the regulations and guidelines established by this committee. The owners of the farm animals from which samples were taken gave permission for their animals to be used in this study. For experiments involving human participants (bacteria specimen), this study was approved by the Chinese Academy of Sciences human ethics committee, and was carried out strictly in accordance with the approved guidelines. Informed consent was obtained from the hospital.

\section{Funding}

This study was supported by the National Natural Science Foundation of China (Grant No. 31072170) and the Natural Science Foundation of Tibet (Grant No. 2016ZR-15-62).

\section{Publisher's Note}

Springer Nature remains neutral with regard to jurisdictional claims in published maps and institutional affiliations.

Received: 19 March 2018 Accepted: 29 June 2018

Published online: 17 July 2018

\section{References}

1. McMillan K, Moore SC, Mcauley CM, Fegan N, Fox EM. Characterization of Staphylococcus aureus isolates from raw milk sources in Victoria, Australia. BMC Microbiol. 2016:16:169.

2. Deresinski S. Methicillin-resistant Staphylococcus aureus: an evolutionary, epidemiologic, and therapeutic odyssey. Clin Infect Dis. 2005;9(2):562-73.

3. Xing XN, Zhang Y, Wu Q, Wang X, Ge WP, et al. Prevalence and characterization of Staphylococcus aureus isolated from goat milk powder processing plants. Food Control. 2016;59:644-50.

4. Stefan M, Geoffrey C, Shore AC, Coleman DC, Patrick A, et al. A field quide to pandemic, epidemic and sporadic clones of methicillin-resistant Staphylococcus aureus. PLoS ONE. 2011;6(4):e17936.

5. DeLeo FR, Otto M, Kreiswirth BN, Chambers HF. Community-associated meticillin-resistant Staphylococcus aureus. Lancet. 2010;375:1557-68.

6. Fitzgerald JR. Livestock-associated Staphylococcus aureus: origin, evolution and public health threat. Trends Microbiol. 2012;20(4):192-8.

7. Cuny C, Wieler LH, Witte W. Livestock-associated MRSA: the impact on humans. Antibiotics. 2015;4(4):521-43.

8. Hammad AM, Watanabe W, Fujii T, Shimamoto T. Occurrence and characteristics of methicillin-resistant and-susceptible Staphylococcus aureus and methicillin-resistant coagulase-negative staphylococci from Japanese retail ready-to-eat raw fish. Int J Food Microbiol. 2012;156(3):286-9.

9. Argudín MA, Mendoza MC, Gonzálezhevia MA, Bances M, Guerra B, et al. Genotypes, exotoxin gene content, and antimicrobial resistance of Staphylococcus aureus strains recovered from foods and food handlers. Appl Environ Microbiol. 2012;78(78):2930-5.

10. Rhee $\mathrm{CH}$, Woo GJ. Emergence and characterization of foodborne methicillin-resistant Staphylococcus aureus in Korea. J Food Protect. 2010;73(12):2285-90.

11. Basanisi MG, La BG, Nobili G, Franconieri I, La SG. Genotyping of methicillin-resistant Staphylococcus aureus (MRSA) isolated from milk and dairy products in South Italy. Food Microbiol. 2017:62:141-6.

12. Judith K, Beatrix S, Monika G, Georg W, Othmar B, et al. Staphylococcus aureus entrance into the dairy chain: tracking $S$. aureus from dairy cow to cheese. Front Microbiol. 2016;7:1603.

13. Lim SK, Nam HM, Jang GC, Lee HS, Jung SC, et al. Transmission and persistence of methicillin-resistant Staphylococcus aureus in milk, environment, and workers in dairy cattle farms. Foodborne Pathog Dis. 2013;10(8):731-6.

14. Ayele Y, Gutema FD, Edao BM, Girma R, Tufa TB, et al. Assessment of Staphylococcus aureus along milk value chain and its public health importance in Sebeta, central Oromia, Ethiopia. BMC Microbiol. 2017;17:141.

15. Sergelidis D, Papadopoulos T, Komodromos D, Sergelidou E, Lazou T, et al. Isolation of methicillin-resistant Staphylococcus aureus from small ruminants and their meat at slaughter and retail level in Greece. Lett Appl Microbiol. 2015;61(5):498-503.

16. Osman K, Badr J, Almaary KS, Moussa IMI, Hessain AM, et al. Prevalence of the antibiotic resistance genes in coagulase-positive-and negativeStaphylococcus in chicken meat retailed to consumers. Front Microbiol. 2016;7:1846.

17. Buyukcangaz E, Velasco V, Sherwood JS, Stepan RM, Koslofsky RJ, et al. Molecular typing of Staphylococcus aureus and methicillin-resistant $S$. aureus (MRSA) isolated from animals and retail meat in North Dakota, United States. Foodborne Pathog Dis. 2013;10(7):608-17.

18. Igbinosa EO, Beshiru A, Akporehe LU, Oviasogie FE, Igbinosa OO. Prevalence of methicillin-resistant Staphylococcus aureus and other 
Staphylococcus species in raw meat samples intended for human consumption in Benin City, Nigeria: implications for public health. Int J Environ Res Public Health. 2016;13(10):949.

19. Schmidt T, Kock MM, Ehlers MM. Molecular characterization of Staphylococcus aureus isolated from bovine mastitis and close human contacts in South African dairy herds: genetic diversity and inter-species host transmission. Front Microbiol. 2017;8:511.

20. Holtfreter S, Grumann D, Balau V, Barwich A, Kolata J, et al. Molecular epidemiology of Staphylococcus aureus in the general population in Northeast Germany: results of the study of health in Pomerania (SHIPTREND-0). J Clin Microbiol. 2016;54(11):2774-85.

21. Ye XH, Fan YP, Wang XL, Liu WD, Yu HF, et al. Livestock-associated methicillin and multidrug resistant $S$. aureus in humans is associated with occupational pig contact, not pet contact. Sci Rep. 2016;6:19184.

22. Li J, Jiang NS, Ke YB, Feßler AT, Wang Y, et al. Characterization of pigassociated methicillin-resistant Staphylococcus aureus. Vet Microbiol. 2017:201:183-7.

23. Song Z, Gu FF, Guo XK, Ni YX, He P, et al. Antimicrobial resistance and molecular characterization of Staphylococcus aureus causing childhood pneumonia in Shanghai. Front Microbiol. 2017:8:455.

24. Xiao YH, Giske CG, Wei ZQ, Shen P, Heddini A, et al. Epidemiology and characteristics of antimicrobial resistance in China. Drug Resist Update. 2011;14(4-5):236-50.

25. Cheng H, Yuan WC, Zeng FY, Hu QW, Shang WL, et al. Molecular and phenotypic evidence for the spread of three major methicillin-resistant Staphylococcus aureus clones associated with two characteristic antimicrobial resistance profiles in China. J Antimicrob Chemother. 2013;68(11):2453-7.

26. Goerke C, Esser S, Kummel M, Wolz C. Staphylococcus aureus strain designation by agr and cap polymorphism typing and delineation of agr diversification by sequence analysis. Int J Med Microbiol. 2005;295(2):67-75.

27. Alashmawy MA, Sallam KI, Abdelghany SM, Elhadidy M, Tamura T. Prevalence, molecular characterization, and antimicrobial susceptibility of methicillin-resistant Staphylococcus aureus isolated from milk and dairy products. Foodborne Pathog Dis. 2016;13(3):156-62.

28. Cana HY. Detection of enterotoxigenic and antimicrobial resistant $S$. aureus in Turkish cheeses. Food Control. 2012;24(1-2):100-3.

29. Cui SH, Li JY, Hu CQ, Jin SH, Li FQ, et al. Isolation and characterization of methicillin-resistant Staphylococcus aureus from swine and workers in China. J Antimicrob Chemother. 2009:64(4):680-3.

30. Petrelli D, Repetto A, D'Ercole S, Rombini S, Ripa S, et al. Analysis of meticillin-susceptible and meticillin-resistant biofilm-forming Staphylococcus aureus from catheter infections isolated in a large Italian hospital. J Med Microbiol. 2008:57(Pt 3):364-72.

31. Abdalrahman LS, Stanley A, Wells H, Fakhr MK. Isolation, virulence, and antimicrobial resistance of methicillin-resistant Staphylococcus aureus (MRSA) and methicillin sensitive Staphylococcus aureus (MSSA) strains from Oklahoma retail poultry meats. Int J Env Res Pub Heal. 2015;12(6):6148-61.

32. Stein $\mathrm{GE}$, Babinchak T. Tigecycline: an update. Diagn Microbiol Infect Dis. 2013;75(4):331-6

33. Kim YJ, Oh DH, Song BR, Heo EJ, Lim JS, et al. Molecular characterization, antibiotic resistance, and virulence factors of methicillin-resistant Staphylococcus aureus strains isolated from imported and domestic meat in Korea. Foodborne Pathog Dis. 2015;12(5):390-8.

34. Eladawy H, Ahmed M, Hotzel H, Monecke S, Schulz J, et al. Characterization of methicillin-resistant Staphylococcus aureus isolated from healthy turkeys and broilers using DNA microarrays. Front Microbiol. 2016;7(7):2019.

35. Wendlandt S, Kadlec K, Feßler AT, Monecke S, Ehricht R, et al. Resistance phenotypes and genotypes of methicillin-resistant Staphylococcus aureus isolates from broiler chickens at slaughter and abattoir workers. J Antimicrob Chemother. 2013;68(11):2458-63.

36. Kehrenberg C, Schwarz S. Distribution of florfenicol resistance genes fexA and cfr among chloramphenicol-resistant Staphylococcus isolates. Antimicrob Agents Chemother. 2006;50(4):1156-63.

37. Deng FR, Wang HW, Liao YF, Li J, Feßler AT, et al. Detection and genetic environment of pleuromutilin-lincosamide-streptogramin a resistance genes in Staphylococci isolated from pets. Front Microbiol. 2017;8(82-e19):234
38. Soaressantos V, Barreto AS, Semedolemsaddek T. Characterization of Enterococci from food and food-related settings. J Food Prot. 2015;78(7):1320-6

39. Chen MY, Felipe L, Liang HQ, Wu RT, Duan JH, et al. Multilevel selection of bcrABDR-mediated bacitracin resistance in Enterococcus faecalis from chicken farms. Sci Rep. 2016;6:34895.

40. Li DX, Wang Y, Schwarz S, Cai JC, Fan R, et al. Co-location of the oxazolidinone resistance genes optrA and cfr on a multiresistance plasmid from Staphylococcus sciuri. J Antimicrob Chemother. 2016;71(6):1474-8.

41. Noushin A, Abolfazl D, Taranehpeimaneh A. Characterization of toxin genes and antimicrobial susceptibility of Staphylococcus aureus isolates in fishery products in Iran. Sci Rep. 2016;6:3421.

42. Oliveira L, Rodrigues AC, Hulland C, Ruegg PL. Enterotoxin production, enterotoxin gene distribution, and genetic diversity of Staphylococcus aureus recovered from milk of cows with subclinical mastitis. Am J Vet Res. 2011;72(10):1361-8.

43. Ikawaty R, Brouwer EC, Duijkeren EV, Mevius D, Verhoef J, et al. Virulence factors of genotyped bovine mastitis Staphylococcus aureus isolates in the Netherlands. Int J Dairy Sci. 2010;5(2):60-70.

44. Qiao YH, Ning X, Chen Q, Zhao RZ, Song WQ, et al. Clinical and molecular characteristics of invasive community-acquired Staphylococcus aureus infections in Chinese children. BMC Infect Dis. 2014;14(1):582.

45. Kraushaar B, Ballhausen B, Leeser D, Tenhagen BA, Käsbohrer A, et al. Antimicrobial resistances and virulence markers in methicillin-resistant Staphylococcus aureus from broiler and turkey: a molecular view from farm to fork. Vet Microbiol. 2017;200:25-32.

46. Wang X, Li X, Liu W, Huang WC, Fu QH, Li M. Molecular characteristic and virulence gene profiles of community-associated methicillin-resistant Staphylococcus aureus isolates from pediatric patients in Shanghai, China. Front Microbiol. 2016;7:1818.

47. Boer ED, Zwartkruisnahuis JTM, Wit B, Huiisdens XW, Neeling AJD, et al. Prevalence of methicillin-resistant Staphylococcus aureus in meat. Int J Food Microbiol. 2009;134(1-2):52-6.

48. Othman HE, Merza NS, Jubrael JMS. Nucleotide sequence analysis of methicillin resistance Staphylococcus aureus in Kurdistan Region-Iraq. Sci J Univ Zakho. 2014;2:65-73.

49. Ahmed OB, Elmekki MA, Omer EE, Elhassan MM. Molecular detection of methicillin resistant Staphylococcus aureus in patients with urinary tract infections in Khartoum State. J Sci Technol. 2014;15:1-8.

50. Clinical and Laboratory Standards Institute (CLSI). Performance standards for antimicrobial susceptibility testing; 26 informational supplement, M100-S26. Wayne. 2016.

51. The European Committee on Antimicrobial Susceptibility Testing (EUCAST criteria). Breakpoint tables for interpretation of MICs and zone diameters. Version 7.0. 2017. http://www.eucast.org. Accessed 13 Mar 2018.

52. Mcdougal LK, Steward CD, Killgore GE, Chaitram JM, Mcallister SK, et al. Pulsed-field gel electrophoresis typing of oxacillin-resistant Staphylococcus aureus isolates from the United States: establishing a national database. J Clin Microbiol. 2003;41(11):5113-20.

53. Perreten V, Kadlec K, Schwarz S, Andersson UG, Finn M, et al. Clonal spread of methicillin-resistant Staphylococcus pseudintermedius in Europe and North America: an international multicentre study. J Antimicrob Chemother. 2010;65(6):1145-54.

54. Zhang K, McClure JA, Elsayed S, Louie T, Conly JM. Novel multiplex PCR assay for characterization and concomitant subtyping of staphylococcal cassette chromosome mec types I to V in methicillin-resistant Staphylococcus aureus. J Clin Microbiol. 2005;43(10):5026-33.

55. Saffari F, Widerström M, Gurram BK, Edebro H, Hojabri Z, et al. Molecular and phenotypic characterization of multidrug-resistant clones of Staphylococcus epidermidis in Iranian Hospitals: clonal relatedness to healthcareassociated methicillin-resistant isolates in Northern Europe. Microbiol Drug Resist. 2016;22:570-7.

56. Hansen LH, Sørensen SJ, Jorgensen HS, Jensen LB. The prevalence of the OqxAB multidrug efflux pump amongst olaquindox-resistant Escherichia coli in pigs. Microb Drug Resist. 2005;11(4):378-82. 